\title{
MUDANÇAS NA UNIDADE PEDIÁTRICA: RELATO DE EXPERIÊNCIA DE INTEGRAÇÃO DOCENTE-ASSISTENCIAL
}

Edelia del Pilar Neira Huerta*

NEIRA HUERTA, E. del P. Mudanças na unidade pediátrica: relato de experiéncia de integraçăo docente -assistencial. Rev. Esc. Enf. USP. v.30, n.3, p.356-70, dez. 1996.

A partir da percepção inicial da unidade pediátrica em que acompanhou e supervisionou as atividades práticas desenvolvidas por alunos de graduação em enfermagem, a autora identifica mudanças significativas implementadas nessa unidade, como resultado de uma experiência de genuína integração docenteassistencial.

UNITERMOS: Integraçăo docente-assistencial. Unidade pediátrica. Enfermagem Pediátrica. Ensino em Enfermagem Pediátrica.

\section{INTRODUÇÃO}

Nos anos letivos de 1992 e 1993, na qualidade de Professora Responsável pela disciplina Enfermagem Pediátrica de uma faculdade particular da cidade de São Paulo, acompanhei e supervisionei, na ala assistencial da unidade pediátrica da sociedade hospitalar da qual a faculdade depende, as atividades práticas desenvolvidas na disciplina por alunos do último semestre do curso de graduação, todos eles integrantes da I e II turmas que se formaram nessa faculdade. Nesse período processou-se nessa unidade uma experiência de integração docente-assistencial.

Com o propósito de compartilhar essa experiência com outros enfermeiros que também tentam executar atividades docentes, de pesquisa e de assistência, apresento a seguir relato dessa experiência. Nela identifico três momentos ou fases seqüenciais, que se superpõem no tempo:

- a unidade pediátrica antes do desenvolvimento do processo de mudança;

- a procura de mudanças: o caminho percorrido; e

- os frutos do processo de mudança.

\footnotetext{
* Enfermeira. Mestre em Enfermagem Pediátrica pela Escola de Enfermagem da USP, São Paulo. Ex-Professora Responsável pela Disciplina Enfermagem Pediátrica da Faculdade de Enfermagem do Hospital Israelita Albert Einsten - FEHIAE
} 


\section{PRIMEIROS CONTATOS E PERCEPÇÃO INICIAL DA UNIDADE PEDIÁTRICA}

Meu primeiro contato com a unidade pediátrica assistencial ocorreu por um acaso em junho de 1992. ( Yom minhas duas orientandas do Curso de Especialização em Enfermagem Oncológica precisávamos de um espaço físico para nos reunir e trabalhar no projeto da pesquisa que elas desenvolveriam junto a mães de crianças com problemas oncológicos. () local escolhido foi a salinha dos médicos dessa unidade, na qual uma das orientandas desempenhava suas atividades profissionais. Aproveitei a ocasião para observar algumas características da unidade, como também para formular algumas perguntas a seu respeito.

A planta física era exatamente igual à de qualquer unidade de adultos da instituição: um corredor en toda sua extensão, provido de instalações e balcões para servir de postinho de enfermagem: três enfermarias de seis leitos cada uma: duas enfermarias de isolamento de três leitos cada uma e a salinha dos médicos localizada no final desse corredor.

As adaptações implementadas na unidade diziam respeito principalmente a medidas de proteção das crianças: porta com visor amplo separando a unidade do resto do andar (elevadores, escadas, hall/sala de espera, ala particular e CTI pediátrico); telas metálicas em todas as janelas das enfermarias; vasos sanitários providos de tampa dupla de modo a propiciar uma molhor adequação às dimensões das crianças. Algumas naredes tinham desenhos de motivos infantis alegres e coloridas.

Apesar de ter sido alertada por colegas docentes quanto à dificuldade de trabalhar com as enfermeiras assistenciais da instituição, decidi solicitar essa unidade como campo de estágio onde eu acompanharia os alunos de graduação em seu aprendizado prático da assistência de enfermagem à criança hospitalizada.

Por ser a primeira ve\% que a disciplina seria implementada na faculdade. como também a primeira vez que a unidade pediátrica receberia alunos para desenvolverem atividades práticas, marquei entrevista com a enfermeira encarregada da unidade. Na oportunidade apresentei-lhe o curso de enfermagem pediátrica como havia sido programado, isto $e$, a abordagem pedagogica adotada. abordagem da assistência de enfermagem na disciplina, objetivos do curso e conteúdo programático. bem como os Objetivos do Estágio Supervisionado em Unidade Pediátrica de Internaceão, as Atividades a serem desenvolvidas pelos alunos para atingirem esses objetivos e os instrumentos que seriam utilizados na avaliacão de seu desempenho na unidade (Anexo).

Na ocasião convidei-a também para participar do conteúdo teórico que seria ministrado na disciplina com o tema "Unidado pediátrica: aspectos físicos e organizacionais", comentando-lhe que o tema tinha sido contemplado como um recurso para atender as necessidades de desenvolvimento integral da crianca hospitalizada. Ofereci e forneci-lhe recursos bibliográficos que julguei a auxiliariam, entre eles, "La enfermera y el niño enfermo" (5). 
O período de reconhecimento de campo estendeu-se por duas semanas completas. Isto por acreditar que. além de ser um período importante para conhecer a unidade - seus recursos humanos e materiais, sua dinâmica, suas rotinas e peculiaridades - constituiria um período que permitiria que eu fosse conhecida e reconhecida como um elemento que participaria da vida da unidade durante as semanas em que os alunos desenvolvessem suas atividades práticas.

Durante esse período pude perceber que as crianças dispunham de excelentes recursos, tanto de diagnóstico quanto de tratamento, de alimentação adequada, de roupas coloridas de variados tamanhos. que havia alguns brinquedos de doação à sua disposição e um grupo de voluntáarias dedicadas à recreacão - 2 horas no período da manhã e 2 horas no período da tarde. de segunda a sextafeira - atividade da qual a equipe de enfermagem não participava. Percebí também que a maioria dos funcionários, inclusive as enfermeiras, era acolhedora e carinhosa com as crianças, mas o cuidado emocional oferecido era intuitivo e não consistente, isto é variava de acordo com o funcionário e com a situação. Não era um cuidado centrado nas necessidades decorrontes do nível de desenvolvimento e da experiência individual da criança. mas dependia do adulto que prestava a assistência. A abordagem da assistência de enfermagem na unidade limitava-se a implementação da prescrição médica incluindo as rotinas de higiene, alimentação, verificação de sinais vilais e do peso. as quais a equipe médica prescrevia como "cuidados gerais".

Em geral as mães eram depreciadas na unidade..."elas não sabem cuidar dos filhos... são muito ignorantes": esta era a opinião que prevalecia na equipe da unidade. O horário de visila restringia-se a uma hora diária (das 14 as 15 horas), exceto nas quartas-feiras, quando se procedia a desinfeção da unidade e as visitas cram proibidas.

Em suma, a unidade oferecia muito para se perceber, analisar e refletir, o que para mim representavam excelentes recursos de aprendizagem para os alunos de graduação. Com a intenção de enriquecer ainda mais esses recursos, ainda durante o período de reconhecimento de campo. solicitei às enfermeiras já mencionadas - minha orientanda e a enfermeira encarregada - que guardassem sucata hospitalar não contaminada. como frascos e equipos de soro, buretas, seringas de preparo de medicamentos, etc. e posteriormente, durante o estágio, com o intuito de que as enfermeiras da unidade compreendessem algumas intervenções dos alunos (que não eram implementadas na unidade), como "brincar" com bonequinhos e material de brinquedo terapêutico. realizar entrevistas e interagir terapeuticamente com os pais, implementar visitas domiciliares, etc., no lugar de assumir a assistência de várias crianças ou de assumir a medicação de uma enfermaria ou de toda a unidade, como provavelmente elas esperavam que o fizessem tendo em conta suas próprias experiências discentes, eu lhes levava material bibliográfico pertinente $(3,12,17$ entre outros) na medida em que essas intervenções eram implementadas pelos alunos.

A abordagem dada na disciplina a assistência de enfermagem era diferente daquela dada na unidade. Na disciplina centrava-se na crianca doente e sua família (1). Apesar desta abordagem ser também nova para os alunos, pois o 
ensino nas outras disciplinas da ficuldade centrava-se nas patologias e não nas pessoas doentes, e apesar da dificuldade que para eles representou a proposta de vivenciar o processo de enfermagem en lodas suas lasess, inclusive de avaliação da assistêneia implementada para assim elaborar scu "estudo de caso", um dos instrumentos utilizados para avaliar sou desempenho na disciplina, eles se dedicaram com entusiasmo e. de acordo com suas avaliacõos orais e escritas. o estágio na unidade pediátrica de internascão propiciou inúmeras experiências de aprendizagem efetiva, entre as quais:

- marcar e realizar entrevistas eom as mães (pais) de crianças hospitalizadas na unidade com o objetivo de levantar dados a respeito da vida diária e do atendimento das nocessidades da criança e sua família (oles deviam utilizar o histórico de enfermagen elaborado pela disciplina):

- auxiliar as mães na compreensão de certos comportamentos novos nos filhos hospitalizados, tais como birra, rejeição dos pais, comportamento arredio, etc.:

- solicitar autorizacãopara a permanôncia irrestrita de algumas mães afim de intervir para resgatiar o polacionamento máefilho que se encontrava severamente afetado pola separacão e pola falta de comunicacão efetiva entre eles, particularmente naqueles casos em quo a criança havia sido submetida a procedimentos invasivos o dolorosos sem ter sido preparada para os mesmos;

- utilizar brinquedos o brincadeiras como os melhores recursos de comunicação com a criança tanto para auxiliá-la em sua adaptação à experiência hospitalar como para prepará-la para presedimentos hespitalares potencialmente traumáticos na esfera psico-emocional. ole:

Preocupada e ocupada com meu papel de facilitadora da aprendizagem junto a meus alunos da graduação e com o meu papel de orientadora-pesquisadora junto às alunas de especialização. não pereelsi que as primeiras sementes haviam sido lançadas e que elas tinham encontrado um solo muito fértil naquelas duas enfermeiras antess identilicadass. $\Lambda$ carda novo contato. mais se sensibilizavam com o sofrimento das crianças, consequência da hospitalização e da doença. Este fato ficou em evidência na reunião que realizamos com a enfermeira encarregada com a intenção de analisar o avaliar o que o estáagio na unidade representara para meus alunos, assim como o que a nossa prosença e atividades na unidade representaram para a equipe de enf'ermagem da unidade. Meu objetivo específico era levar em conta suas valiesas olservações no planejamento do estágio para o período letivo seguinte.

Com grande surpresa ouvi sua decidida e suscinta avaliação: a experiência tinha sido muitíssimo enriquecedora para toda a equipo do enfermagem! E ainda mais: manifestou seu grande interesso em ter mães acompanhantes/participantes na unidade. indagando quanto a minha disponibilidade para ministrar algumas aulas para as enfermeiras a esse respeito. Com enlusiasmo aceitei o convite, comentando-lhe apenas que, uma ve\% que na minha percepção as aulas expositivas 
facilitavam a aprendizagem apenas quando atendem a uma forte motivação de quem as assiste. levando-o a participar ativamente das mesmas, eu não acreditava em sua validade como recurso de aprendizagem nessa situação específica.

Assim. propus-Ihe tentar a formação de um grupo de encontro centrado na tarefa (14). Essa tarefa seria a de estudar. analisar. vivenciar e refletir a respeito do tema solicitado. No mesmo dia forneci-lhe apostila sobre grupos operativos na educação (2).

Acredito que as alividades prálicas desenvolvidas pelos alunos da graduação durante seu aprendizado prático na unidade podiátrica assistencial constituiram as sementes decisivas que, ao caírem no terreno l'ortil representado principalmente por aquelas duas enfermeiras sensibilizadas com o sofrimento das crianças no hospital. desencadearam o processo. o movimento de um grupo de enfermeiras em direção a conquistia de mudancias em sua realidade profissional.

\section{O PROCESSO DE MUDANÇA}

Na primeira quinzena de janeiro de 1993 teve lugar o nosso primeiro encontro, do qual participaram dez enfermeiras, incluindo a enfermeira encarregada. lista tinha me comentado que as enfermeiras aguardavam ansiosas nossa primeira reunião solore mães acompanhan les. Su havia lido contato apenas com quatro delas: outras, conhecia apenas do vista. o às demais fui apresentada nessa ocasião. Sabia que nem todas elas concordavam com a importância da presença das mães na unidade. Por esta razão, ao preparar-me para esse primeiro encontro, além de selecionar material biblingráfico a respeito do assunto $(1,6,7,8,9,10,11,13,17)$, julguei necessário levar para o encontro uma mensagem que me pareceu essencial transmitir-lhes desde o primeiro momento:

"Todo processo de mudança exige da equipe que o implanta conscientização. criatividade e particularmente motivaç̃o para quo assim possa enfrentar os eventuais percalças que, com certeza, surgirão duranteo períndo de implantação" (13).

Atraves desta mensagem pretendia enliatizar a necessidade de um grupo fortemente motivado para mudar. Pretendia tambem esclarecer que as mudanças, para serem profundas e duradouras. não podiam ser impostas por chefias motivadas e que, para que essas mudanças so viabilizassem. o caminho a ser percorrido seria provavelmente longo e dilísil e que quiçá nem todas as expectativas seriam alcançadas. "Tudo dependeria do grupo, de cada um de seus integrantes e que, a princípio. meu papel se limitaria a prestar assessoria, compartilhando com o grupo minhas experiências e conhecimentos no assunto na medida em que assim necessário fosse.

Deveria tamben me empenhar em criar um clima onde aquelas colegas que se sentiam apenas "obrigadas" a participar dos encontros se sentissem livres para expressar suas percepções. suas idéias e seus sentimentos.

Coloquei para o grupo que haveria necessidade de sermos pacientes para acompanhar o ritmo, provavelmente lento o eom até eventuais regressões, do caminhar de cada um dos integrantes do grupo: que estávamos, enfim, apenas iniciando uma longa caminhada que. com certéa. nos ofereceria obstáculos e desafios. 
Nessa primeira reunião dediquei-me tamberm a conhecer o grupo o suas expectativas a respeito da minha participação. Respondi às suas questões. preocupações e dúvidas atraves do cam inho que cu própria percorrera em relação d percepção e assistência de enfermagem aos pais, inclusive com minha experiência de pesquisadora no assunto $(6,7,8.9,10,11)$. Assim, teci alguns breves comentários sobre a importância que eu percebia na presença da mãe e dos cuidados maternos para a criança hospitalizada, particularmente para aquelas de ate 5 anos, e apresentei resumidamente meu modo de perceber, tratar e assistir os pais nas diferentes situações - admissão hospitalar, visita, mãe acompanhante e alta hospitalar.

A seguir ofereci o material bibliográfico que havia selecionado para essa ocasião, sugerindo que o grupo trabalhasse com ele como achasse mais conveniente e produtivo, colocando também minha posição pessoal de realizar encontros periódicos, com a freqüência que fossse sen tida pelo grupo como necessária e em um clima de abertura para colocar experiências, sentimentos, necessidades e dificuldades pessoais no trabalho e no relacionamento com os pais e com os funcionários e demais membros da equipe em relação à presença dos pais na unidade.

Uma das participantes desse primeiro encontro sugeriu trabalhar cada texto e que o grupo se dividisse para ap resent também que estas fossem implementadas uma vez por semana. Assim, a tarefa do grupo e sua periodicidade, bem como seu papel no grupo foram definidos; eu deveria assessorar o grupo com as meus conhecimentos e experiências na medida em que assim fosse solicitado e, principalmente, deveria coordenar as reuniōes, criando as condições, o clima de abertura que facilitasse para o grupo seu progredir em seu movimento em direção a conquista de mudanças. Deveria esse ser um clima do aceitação, de compreensão, respoito. conliança o liberdade para sentir, refletir e $\operatorname{agir}(14,15,16)$.

No segundo encontro iniciou-se a apresentacão dos textos e, para minha surpresa, oprimeiro texto a ser apresentado não formava parte do material que eu selecionara. Tratava-se de "La enfermera y el niño enfermo" (5), texto que, como já relatado, eu fornecera vários messes antess à enfermeira encarregada; ficara assim em evidência o impacto que sua leitura havia provocado nessa enfermeira.

O grupo como espaço para sentir, pensar o querer, como espaço para ser, em um clima de liberdade e de aceitação do(s) outro(s), emergiu já nesse segundo encontro. $\mathrm{Na}$ apresentação desse primeiro texto manifestava-se a subjetividade das apresentadoras que, talvez sem o perceberem, explicitavam sua resistência à presença contínua das mães na unidade atraves de comentários como os que se seguem:

- "há escassez de enfermeiras... por exemplo, e comum a ocorrência de duas ou mais internações simultâneas... como fiea então a entrevista aos pais na admissão da crianşa?":

- "adoro trabalhar com crianças. mas os pais só atrapalham"; 
Nesse segundo encontro, "somente" o texto citado foi apresentado, analisado e exaustivamente discutido. A apresentação do segundo texto foi apenas iniciada. Este fato gerou preocupação na enfermeira encarregada, para quem novamente insisti em minha crença de que na busca de mudanças profundas não é possivel predeterminar prazos ao movimen lo. à caminhada do grupo. Vale a pena mencionar que a enfermeira encarregada havia providenciado retroprojetor para a ocasião: em sua expectativa julgou que este seria necessário para auxiliar as responsáveis por apresentar us primoiros toxtos. porém estas não the conferiram a mesma importância que a enfermeira encarregada tinha atribuído ao seu conteúdo.

No terceiro encontro deu-se continuidade a apresentação, análise e discussão dos textos. Nessa oporiunidade foram vários os lextos trabalhados pelo grupo, e as responsáveis polas apresentações. que na minha percepção eram desde o início as mais motivadas para as mudancas almejadas. tinham preparado inclusive transparências para facilitar a compreensão por parłe dos colegas. Só que dessa vez não havia retroprojetor. (... estaria a enfermeira encarregada revendo, ponderando suas expectativas em relação ao grupo?).

Nessa terceira reunião discutiram-so amplamente as técnicas de comunicação efetiva com os pais (16.17). discussão que facilitou a identificacão e. conseqüentemente a tomada de consciência de vários preconceitos em relação aos pais das crianças que eram internadas na unidade pediátrica assistencial. Nesse encontro emergiram tambem outras questões de enfermagem pediatrica, entre as quais: o que fazer com as crianças que apresentavam crises de birra na unidade pediátrica?

Ao avaliar esse terceiro encontro. evidenciaram-se duas atitudes distintas entre os participantes. ambas poróm inclicativas de movimento, atitudes estas sintetizadas nas duas verbalizacenes a seguir:

- "falta mais... a situação com as mães ó dilicil o o funcionário não aceita" (e importante destiacar que a fala anterior desta colega era "... os pais só atrapalham"); e

- "estas reuniões representam para mim um despertar para a reflexão sobre o quê se faz protissionalmente",

A partir do quarto encontro a apresentação de textos foi abandonada sem ninguém fazer referência ao fato. () grupo, talvez sem percebê.lo, estava mudando o rumo de sua caminhada: para os encontros, no lugar de textos, eram trazidas vivencias concretas que o grupo comentava, analisava, propondo também alternativas de intervenção. mas sem críticas. Surge interesse genuíno na experiência da colega. dando assim início a uma intensa troca de experiências, troca de percepcões, de ideias o de sentimentos, que invariavelmente levavam o grupo a refletir sobre sua aluação e desempenho profissionais. Deste modo, através da troca de experiências, emergiam novos interesses, discutiam-se os mais variados temas de enfermagem pediálrica, mas sem deixar de lado a tarefa original: ter mães acompanhantes/participantes na unidade. 
Entre os temas discutides, caho mencionar:

- relacionamento: enformeira-crianca: enfermoira-mães (pais): enfermeiracolegas; enfermeira-chefia de enformagem: enfermeira-equipe médica: enfermeirafuncionários; enfermeiras-Instituição (normas. regulamentos... "harroiras"):

- estimulacão da criança pequena:

- instrumentos de avaliacão do desenvolvimento da criança:

- preparo da crianca para procedimenlos doloressos ou geradores de estresse:

- cuidado emocional da criansai no hosnital o a intervenção de enfermagem nester cuidado;

- utilizacão de lrrinquedos o brincadeirass pola enfermeira na assistência à criança hospitalizada, ete.

$\Lambda$ cada novo encontro ampliava-se a percepeão do grupo em relacão ao ser

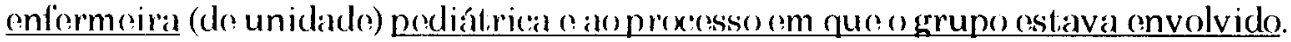
$\Lambda$ cada novo encontro. novas vivências. novas análises e. como conseqüência. discussões e reflexões cadla vez mais prolundas: ludo em um clima de apoio, isento de críticas e. cada vez mais. aproveitando a ocasião dos encontros para levar as últimas vivêneias concrolas na busea de novas reflexões e de alternativas de intervenção.

Lisse foi o cam inho pereorrido pelo grupo no inluilo de conquistar mudancas: o caminho de um grupo demoxático. de participacão aliva onde as diferenças hierarquicas ficaram de fora: ondo foi possível ser espontâneo e autêntico, sem medo de críticas. onde pudemos ser quem eramos: enfermeiras-pessoas com recursos o fraquezas: com habilidades o limilacones. caminho esse que levou à união no grupo, elem ento essencial quando se quer agir como agentes catalisadores de mudanceas. Foi este grupo de encontros que faciliter a reflexão. requisito fundamental para a acaia passes estes essenciais para a aprendizagem efeliva e duradoura para o crescimento profissional. Foi esse o caminho que permitiu identificar a vonlade de mudar e que forneceu a energia, a forca e a sabedoria necessárias para em conjunlo e a partir das vivôncias concretas, refletir. buscar. propor analisar e disculir estrateggias adequadas a implementação de mudanças em nosso universo prolissional.

\section{MUDANÇAS NA UNIDADE PEDIÁTRICA}

Devido a imposicão da faculdade. om fevereiro de 1994. fui obrigada a desistir da minha parlicipacão no grupo de encontros. Por esse motivo. a experiencia aqui rolatada estendeu-se por apenas treze meses: entretanto, apesar do curto poríodo. ela propiciou inúmeras mudanças na unidade pediátrica assistencial. A seguir. identifico aquelas que julgo mais significativas:

- Mudanca do porcensão em relacão à presenca e à participacão dos pais na unidade pediátrica: todas as enformeiras da unidade passaram a perceber os 
pais como pessoas imporlantos. não apenas para a criança hospitalizada, mas também para uma assistêneia de enlormagem holislica. na qual oles tambem são nossos clientess. com quem podemos o devemos implementar educacão para a

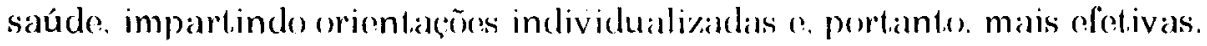

Como reflexo desta mudanca de pereepeão nas enfermeiras. os funcionários não apenas os aceilam molhor. como fambóm passaram a valorizar sua presenca na unidade, estimulando-os a ficarom junto ao l'ilho: já há mãos aleompanhantes/ participantes na unidade pediátrical assistoncial!

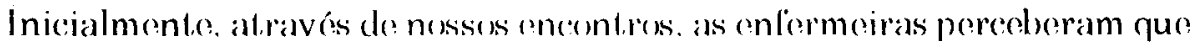
procisavam se preparar molhor para assistir es pais e por outrolado. que deveriam agir com cautola em vista das harroiras da instituicão. Assinn. a mudanca processou-se gradativamente: definiram primeirocriterios para solecionar quais as mães que permaneceriam mais tempo que o pormilido para a visita diaria. o qual foi ampliado de uma para qualro horas (das 14 as 18 horas): as mães de

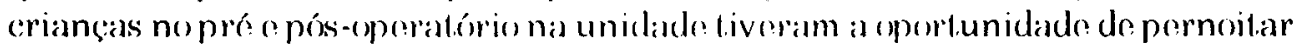
na unidade so assim thos fosso convonionte o possívol. a as mães de criancas portadoras de problemas oncológricas em quimionerapia tamberm foram permilidas de permanecer junto a seus filhos diariamente. das 8 as 18 horas.

Com a adocão desses criberios as enlermoiras criaram para si próprias uma situacão mais scgura para freinarem a assistoncia do enformagem aos pais. Simultanoamente com o propósito de demonstrar a instituicão a importâneia da presenga dos pais na unidade. as enlormoiras desenvolvoram pesquisa junto a cinqüenta mães. () oljet.jvo foi atingrido em plenitude. lanto que. no momento. favorece-se a permanência na unidade de lodas as mães que assim o desejarem. e as enformeiras continuam a so emponhar na procura de solucoóces para os transtornos decorrentes da falta de acemodapones apropriadas. de uso excelusivo para as mães. oferecendo-thes o banheilo de funceionários a a pessibilidade de

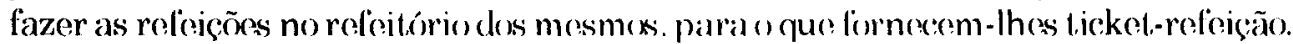

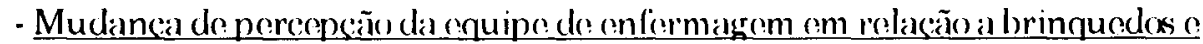
brincadeiras na unidade pediátriea: estes não mais são pereobidos como mera atividade recreativa, lazer ou simples passallempo: passaram a colorar uma dimensão muito mais abrangente. sendo alualmonto perechides como instrumentos do desenvolvimento da criangaj em lodess sous soleres (neuro-psico-motor). comoomelhor recurso de comunicação com a crianca. bem como pokleroso recurso terapêtico a ser utilizado pela enfermeira na assistência a criança hospilalizada.

Esta mudança de pereopãa em rolaça ao brinear na infâneia grerou no grupo a necessidade do um troinamento para preparo da cerianca para on frentar

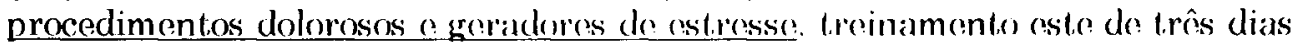
de duraşão, implementado em cluas oporlunidades (junho e julho de 1993) de modo que todas as enfermoiras. inclusive aquelas alastiadas devido a ferias. folgas ou licencas, tivessem a oporlunidade de participar. () ireinamento foi conduzido por uma psicóloga com a minha colalouração ativa. 
- Mudancas no ambiente físico: como resultado da mudança de percepção em relação a brinquedos e brincadeiras, o hall do andar pediátrico, antes mobiliado como sala de espera com poltronas para adultos, foi transformado em uma área fechada destinada à recreacão, com mobília e brinquedos adequados às características de desenvolvimento das crianças, área esta que é respeitada pela equipe toda como "area neutra", na qual nenhum procedimento, doloroso ou não, é executado. Vale mencionar que esta área foi também muito bem-vinda pelas crianças da ala particular e suas famílias.

Houve também reformas na unidade: foram construídos visores entre as diferentes enfermarias, facilitando assim a observação à distância dos comportamentos das crianças, de seus pais e da própria equipe, possibilitando deste modo uma intervenção mais oportuna e mais efetiva. Para tornar o ambiente mais acolhedor e estimulante, todas as paredes, inclusive e em especial as da área de recreação, ganharam desenhos coloridos e adequados. Começou também um grande empenho por parte das enfermeiras em conseguir um ambiente privativo para a realização de entrevistas com os pais da criança na admissão hospitalar, bem como para desenvolver relacionamento terapêutico com aqueles que apresentassem essa necessidade.

- A abordagem da assistência de enfermagem iniciou um processo de gradativa transicão de uma abordagem centrada em patologias para uma abordagem centrada na crianca doente: as enfermeiras começaram a perceber as necessidades de desenvolvimento da criança hospitalizada, entre as quais, as psicoemocionais. Emergiu assim a necessidade de se dispor de dados que permitissem atender essas necessidades e, com esse objetivo, algumas enfermeiras, de acordo com suas percepções e conhecimentos, elaboraram um histórico de enfermagem, que foi discutido no grupo e testado no momento da admissão por todas as enfermeiras. As experiências individuais eram levadas aos encontros do grupo, ocasião em que as dificuldades eram discutidas e onde o grupo aprofundava seus conhecimentos e habilidades nas técnicas de comunicação necessárias a coleta de dados na entrevista com os pais.

As enfermeiras sentiram forte necessidade de "contagiar/contaminar" o maior número possível de colegas de unidades pediátricas com esta nova percepção da criança doente. Para atender essa necessidade, o grupo organizou, divulgou e coordenou, em maio de 1993, um curso de extensão universitária sobre intervencão de enfermagem no cuidado emocional da crianea hospitalizada. Nas palestras proferidas participaram docentes da disciplina de Enfermagem Pediátrica da Escola de Enfermagem da USP e do Departamento de Enfermagem da Escola Paulista de Medicina. Uma das palestras, acerca dos aspectos físicos e de organização da unidade pediátrica, foi preparada e apresentada por três enfermeiras membros do grupo de encontro sob a orientação da assessora do mesmo.

- Descoberta da enorme importância do relacionamento e das técnicas de comunicação efetiva, não apenas para a qualidade da assistência à criança 
hospitalizada e sua família, mas também para a assistência à criança sadia, no relacionamento entre colegas, com funcionários, com todos os membros da equipe hospitalar, como também na vida pessoal. Não raro eram levadas aos encontros vivências "domésticas" de relacionamento, particularmente com os filhos.

Como resultado da troca de experiências e da reflexão sobre as mesmas que tinham lugar nos encontros, as enfermeiras tomaram consciência de sua necessidade de comunicação mais objetiva e mais participativa e, conseqüentemente, mais efetiva com a equipe multidisciplinar da unidade. Assim, em início de setembro de 1993 teve lugar a primeira reunião multidisciplinar na unidade, reunião esta convocada pelas enfermeiras, com objetivos claramente definidos e cuja duração ultrapassou as duas horas. As enfermeiras abandonaram também sua atitude passiva, passando a participar ativamente de visita médica semanal.

- Descoberta da importância do "grupo" como fonte de apoio e crescimento profissional, como recurso facilitador de reflexão e de aprendizagem e como forca mediadora de mudancas. esta importância evidenciou-se em outubro de 1993 com a criação do "Grupo de Apoio e Desenvolvimento Profissional das Enfermeiras de Pediatria", do qual eu fui especialmente convidada a fazer parte na qualidade. de assessora e facilitadora das condições necessárias para o grupo funcionar (14). Na ocasião foi dedicado um encontro à definição dos objetivos do grupo, encontro esse que na realidade significou mais um momento de reflexão sobre o quê o grupo representava para cada uma das enfermeiras, como também de suas expectativas em relação ao mesmo.

- As enfermeiras da unidade passaram a valorizar muito mais seu afazer profissional junto às crianças, às mães, dentro da equipe multidisciplinar e com os funcionários. Em outras palavras, elas começaram a obter maior gratificacão, estímulo e motivação de seu desempenho como enfermeiras de unidade pediátrica. A experiência no grupo levara-as a atingir a categoria de necessidade de realizacão pessoal (13), e a maioria delas manifestou, em repetidas ocasiões, sua grande motivação em cursar Enfermagem Pediátrica a nível de Especialização com a autora e sua abordagem pedag6gica e assistencial. Em duas oportunidades inclusive manifestaram por escrito esta motivação à gerência de enfermagem da instituição, solicitando a implementação desse curso. Este não teve lugar devido aos obstáculos representados apenas pela faculdade a nivel de coordenação, que não o autorizou.

- Várias enfermeiras demonstraram grande interesse no desenvolvimento e implementacão de pesquisas na unidade pediátrica: "Utilização do brinquedo pela enfermeira na assistência à criança hospitalizada"; "Mães no CTI pediátrico", etc., bem como em participar ativamente de eventos da categoria, apresentando trabalhos de divulgação científica (I Jornada de Enfermagem em Cirurgia Pediátrica, $4^{\circ}$ ENFTEC, etc.). Tanto nos projetos e desenvolvimento de pesquisas quanto no preparo dos trabalhos cientificos, fui solicitada e atuei como orientadora e co-autora. 
- Integracão entre as enfermeiras assistenciais e a docente: fora as mudanças já apontadas, todas as quais refletem integração docente-assistencial (IDA), as enfermeiras, além de acolherem à docente e ao grupo de alunos como membros da equipe da unidade, passaram a se interessar cada vez mais pelo ensino, tanto a seus funcionários, às crianças e suas famílias, como também facilitando o aprendizado prático dos alunos na unidade - particularmente na utilização de equipamentos novos e sofisticados - e participando também das aulas teóricas, algumas das quais elas ministraram.

Outros comportamentos das enfermeiras também evidenciaram esse interesse: após consultarem a respeito de datas e horários, tanto a enfermeira encarregada quanto outras colegas da unidade, inclusive da ala particular, acompanharam espontaneamente a apresentação e a avaliação dos estudos de caso implementados pelos alunos com crianças da unidade pediátrica assistencial.

Também, com o objetivo de que os alunos avaliassem a unidade em seus diferentes aspectos, a enfermeira encarregada marcou e realizou reunião com todos as grupos que estagiaram na unidade. Invariavelmente, nessa oportunidade os alunos verbalizaram sem receios, tanto os aspectos positivos quanto os negativos por eles percebidos durante suas atividades práticas. Dessa forma, todos esses grupos de alunos puderam colaborar no enriquecimento da unidade como recurso de aprendizagem, uma vez que todas as suas colocações foram altamente consideradas e, quando possível, viabilizadas pela enfermeira encarregada. Assim, ocaminho a ser trilhado por futuras turmas na unidade encontrava-se preparado!

\section{CONCLUSÃO}

A experiência apresentada neste relato não é resultado de um programa de IDA, nem segue nenhum dos modelos preconizados na literatura (4). Ela é conseqüência de integração espontânea e crescente, e por isso mais verdadeira e autêntica.

Todas as mudanças na unidade pediátrica identificadas neste trabalho demonstram que a experiência contribuiu para:

1. melhorar a qualidade da assistência de enfermagem;

2. estimular o processo de ensino de enfermagem tanto para os alunos de graduação quanto para os profissionais e funcionários de enfermagem; e

3. encorajar o desenvolvimento de pesquisas na área de assistência de enfermagem.

Essas três contribuicões correspondem às metas da IDA relacionadas por KАЛYАMА (4) e, conseqüentemente, pode-se concluir que a experiência relatada representa uma vivência de genuína IDA.

Para a autora (4), IDA é ainda uma estratégia de mudanca para modernização do processo educacional que pode chegar a satisfazer as necessidades 
de saúde da comunidade através de um processo de ensino-aprendizagem construído a partir das vivências na prestação de serviços. Segundo KAJIYAMA (4), isto leva a uma filosofia educacional crítica e reflexiva que, por sua vez, permite a compreensão e posterior transformação do processo educacional.

Os frutos da experiência apresentados neste relato implicam em mudancas significativas de percepção de conhecimentos e de habilidades. É esse tipo de mudanças que evidencia a ocorrência de aprendizagem efetiva e duradoura, do autêntico crescimento profissional (e pessoal).

Como KAJIYAMA (4), acreditamos que a melhor maneira de favorecer o relacionamento entre o enfermeiro docente e o enfermeiro assistencial afim de que possam trabalhar juntos é a colaboracão mútua, cada qual tentandoprogredir em sua carreira sem se tornar um empecilho, e sim um facilitador do desenvolvimento do outro. Essa é a verdadeira essência implícita nesta experiência!

NEIRA HUERTA, E. del P. Changes in the Pediatric unit: report of an experience os nursing teaching and nursing practice integration. Rev. Esc. Enf. USP, v.30, n.3, p.356-70, dec. 1996.

The author identifies significant changes in a pediatric unit in which she supervised the practical activities developed by undergraduate students, as a result of true nursing teaching and nursing practice integration.

UNITERMS: Nursing teaching and nursing practice integration. Pediatric unit. Pediatric Nursing. Nursing teaching.

\section{REFERÊNCIAS BIBLIOGRÁFICAS}

1. ELSEN, I.; PATRÍCIO, Z. M. Assistência à criança hospitalizada: tipos de abordagem e suas implicaçōes para a enfermagem. In: SCHMITZ, E. M. et al. A enfermagem em pediatria e puericultura. Rio de Janeiro, Atheneu, 1989, cap. 15

2. FALSETTI, L. A. V. Educação e grupos operativos. São Paulo, Divisão de Educaçáo do Instituto da Criança do HC-FMUSP, 1978. /mimeografado/.

3. GREEN, C. S. Understanding children needs through therapeutic play. Nursing, Horsham, v. 4, n. 10, p. $31-2,1974$

4. KAJIYAMA, H. Estudo das atividades do docente de enfermagem no programa de integraçăo docente-assistencial. São Paulo, 1991, 184 p., Tese (doutorado) - Escola de Enfermagem da Universidade de São Paulo.

5. MARLOW, D. La enfermera y el niño enfermo. In: MARLOW, D. Enfermaría Pediátrica. 4 ed., México, Interamericana, 1975, p. 56-67. 
6. NEIRA HUERTA. E. del P. Intermação conjunta: critérios para decisão sobre que mães poderão acompanlar seus fillos durante a internação. Rev. Esc. Enf. USP. v. 17, n. 3. p. 213-27. 1983.

7.

A experiência de acompanhar un fillo hospitalizado: sentimentos. necessidades e expectativas manifestados por mães acompanliantes. Săo Paulo. 1984. 218 p.. Dissertação (mestrado) - Escola de Enfermagem da Universidade de São Paulo.

8. Reflexões sobre o comportamento das enfermeiras perante as mães na unidade pediátrica. Rev. Esc. Enf. USP. v. 18, n. 1. p. 209-14. 1984.

9 Interaçōes entre enfermeiras e pais de crianças hospitalizadas. Rev. Esc. Enf. USP. v. 19. 11. 1. p. 81-93. 1985.

10 A experiência de acompanhar un filho hospitalizado: sentimentos. necessidades e expectativas manifestados por mães acompanhantes. Rev. Esc. Enf. USP. v. 19. 11. 2. p. 153-71. 1985

11 Pesquisa junto a mães acompanhantes: reflexões sobre os resultados obtidos. Rev. Esc. Enf. USP. v 19. 11. 3. p. 225-9, 1985.

12 Briuquedo no hospital. Rev. Esc. Enf. USP. v. 24, n. 3.

p. $319-28,1990$

13. PETRILLO. M.: SANGER, S. Cuidado emocional del niño hospitalizado. México. Prensa Médica, 1975.

14. ROGERS, C. R. Tornar-se pessoa. 4 ed. São Paulo. Martins Fontes, 1980

15. Giupos de encontro. 4 ed.. São Paulo. Martins Fontes. 1982.

16. Liberdade de aprender em nossa década. Porto Alegre. Artes Médicas, 1985.

17. WHALEY, L. F.: WONG, D. L. Nursing care of infants and children. 4 th ed., St. Louis, 1991. 


\section{ANEXO \\ DISCIPLINA ENFERMAGEM PEDIÁTRICA}

\section{ESTÁGIO SUPERVISIONADO EM UNIDADE PEDIÁTRICA DE INTERNAÇÃO}

$\mathrm{N}^{\circ}$ Alunos: 5 por grupo.

Horário: das 6:45 às 13:00 hrs.

Período: a partir da $1^{\mathrm{a}}$ semana de curso

\section{OBJETIVOS DO ESTÁGIO:}

- Estabelecer e manter comunicas̆a torapêutica com a criança hospitalizada e. sua família.

- Avaliar as condições físicas e o desenvolvimento da criança hospitalizada nas diferentes faixas etárias.

- Avaliar as necessidades da criança hospitalizada o o seu atendimento.

- Prescrever, implementar e avaliar assistência de enfermagem para crianças hospitalizadas.

- Orientar e assistir pais no atendimento das necessidades da criança doente e na promoção de saúde de crianças convalescentes.

- Estabelecer relacionamento profissional com membros da equipe assistencial de unidades pediátricas de internação.

\section{ATIVIDADES A SEREM DESENVOLVIDAS PELOS ALUNOS DURANTE O ESTÁGIO:}

- Exame físico geral e segmentário da criança hospitalizada.

- Avaliação do crescimento e do desenvolvimento da criança.

- Entrevista com responsáveis pelo atendimento das necessidades da criança, obrigatoriamente entre eles, a mãe ou pai.

- Planejamento de assistência de enfermagem (Prescrição de enfermagem).

- Assistência integral de enfermagem à criansa hospitalizada e sua família, aplicando a sistematização da assistência de enfermagem (SAE).

- Reuniões com o grupo de estágio com a finalidade de discutir e/ou apresentar planos de ação.

\section{AVALIACÃO DO ESTÁGIO EM UNIDADE PEDIÁTRICA DE INTERNACÃO:}

Nesta serão utilizados os seguintes instrumentos:

- Boletim de estágio supervisionado;

- Folha de auto-avaliação diária; e

- Trabalho escrito: estudo de caso, que deverá ser elaborado em duplas, respeitando roteiro indicado pela disciplina e apresentado ao grupo na última semana do curso, no horário que for sorteado. 